\title{
Selective Hierarchical Aluminosilicates for Acetalization Reaction with Propylene Glycol
}

\author{
Hartati $^{1}$, Mardi Santoso ${ }^{2}$, Hadi Nur ${ }^{3}$, Leaw Wai Loon ${ }^{3}$, Hasliza Bahruji ${ }^{4}$, \\ Imroatul Qoniah ${ }^{2}$, and Didik Prasetyoko ${ }^{2, *}$
}

${ }^{1}$ Department of Chemistry, Faculty of Science and Technology, Universitas Airlangga, Kampus C UNAIR, Jl. Mulyorejo, Surabaya, 60115, Indonesia

${ }^{2}$ Department of Chemistry, Faculty of Science, Institut Teknologi Sepuluh Nopember, Keputih, Surabaya 60111, Indonesia ${ }^{3}$ Ibnu Sina Institute for Scientific and Industrial Research, Universiti Teknologi Malaysia, Johor Bahru, Malaysia

${ }^{4}$ Centre for Advanced Material and Energy Sciences, Universiti Brunei Darussalam,

Tungku Link Road, BE1410, Brunei Darussalam

\section{* Corresponding author:}

tel: $+62-31-5943353$

email:didikp@chem.its.ac.id

Received: October 26, 2018

Accepted: March 12, 2019

DOI: $10.22146 / \mathrm{ijc} .40106$

\begin{abstract}
Hierarchical micro-mesoporous aluminosilicates nanoparticles were synthesized at different of Si/Al ratios and were directly used as a solid acid catalyst for acetalization reaction with propylene glycol. TEM and $\mathrm{N}_{2}$ adsorption analysis of the resulting aluminosilicates revealed the formation of the hierarchical structure occurs on the Si/Al ratio increases the formation of mesoporous within the structure of aluminosilicate. The aluminosilicates exhibit high selectivity towards acetalization reaction in comparison with the homogeneous PTSA. The presence of mesoporous structures is crucial for increased conversion and selectivity of the reaction which presumably due to the improved diffusion of substrate to reach acid sites.
\end{abstract}

Keywords: hierarchical aluminosilicates; Si/Al; acetalization; propylene glycol

\section{- INTRODUCTION}

Circumventing from the use of the homogeneous acid catalyst in the production of the fine chemical has attracted research in the development of solid acid catalyst. Zeolite, with a variation of silica to alumina molar ratio, offers stability and flexible acidity as an ideal choice of catalyst. Acetalization reaction is the reaction between aldehyde/ketone and alcohol requires Brønsted or Lewis acid catalyst to produce acetal/ketal products [1]. The product from acetalization is often used in fragrance, cosmetics, pharmaceuticals, detergents, lacquer and as an additive in the food and beverages industries [2-4]. The homogeneous acid catalyst is currently employed to serve the purpose and is associated as a corrosive substance that is not only harmful but required careful handling, storage and disposal [5-6]. The use of a solid acid catalyst is beneficial as the catalyst is easily separated from the product and can be re-utilized to reduce the operational cost. For the benefit of health and safety aspect and to reduce the devastating environmental consequences arising from the use of a homogeneous catalyst, numerous studies have been conducted to increase the performance of heterogeneous catalysts in acetalization reactions [7]. MCM-22, Al-MCM-41, AlMSU-Y were among aluminosilicates that have been widely employed to catalyze acetalization reaction [8-13] which the results indicated the catalytic performance was strongly affected by porosity and acidity of the catalysts.

We have previously reported the use of aluminosilicates in acetalization of 3,4-dimethoxy benzaldehyde [14] and in acetalization of furfuraldehyde [15] with propylene glycol which the results showed that the pore diameter and acidity affected the catalytic activity. Here we carried out detail studies on the influence of aluminosilicates with a variation of acidity and hierarchical structure on its activity for acetalization of three aldehyde compounds with propylene glycol and

Hartati et al. 
also on the ketalization reaction with propylene glycol. The aim is to determine the catalytic performance of the aluminosilicate acid catalyst on the variation of substrate structures. The catalytic performance of the assynthesized aluminosilicate was also compared to the homogeneous PTSA catalyst and H-ZSM-5.

\section{- EXPERIMENTAL SECTION}

\section{Materials}

The materials used for acetalization reactions were 3,4-dimethoxy-benzaldehyde, $\left(\mathrm{C}_{9} \mathrm{H}_{10} \mathrm{O}_{3}\right.$, Merck, 99\%, 8.08525.0100); furan-2-carbaldehyde or furfuraldehyde, $\left(\mathrm{C}_{5} \mathrm{H}_{4} \mathrm{O}_{2}\right.$, Sigma Aldrich, 99\%, 185914); (E)-hex-2-enal or trans-2-hexenal, $\left(\mathrm{C}_{6} \mathrm{H}_{10} \mathrm{O}\right.$, Sigma Aldrich, $\geq 95 \%$, W256110); 1-(furan-2-il) ethanone or 2-acetylfuran, $\left(\mathrm{C}_{6} \mathrm{H}_{6} \mathrm{O}_{2}\right.$, Sigma Aldrich, 99\%, A16254); 1-naphthalene-1iletanon or 1-acetonafton, $\left(\mathrm{C}_{12} \mathrm{H}_{10} \mathrm{O}\right.$, Sigma Aldrich, $97 \%$, 276766), and propylene glycol $\left(\mathrm{C}_{3} \mathrm{H}_{8} \mathrm{O}\right.$, Merck, $99 \%$, 8.22324.1000). The toluene was used as a solvent in a chemical reaction $\left(\mathrm{C}_{6} \mathrm{H}_{5} \mathrm{CH}_{3}\right.$, Merck, 99.9\%, 1.08325.2500), and nitrobenzene $\left(\mathrm{C}_{6} \mathrm{H}_{5} \mathrm{NO}_{2}\right.$, Merck, 99\%, 8067700100) was used as internal standard for gas chromatography analysis. The study also used a homogeneous catalyst of $p$ toluene sulfonic acid monohydrate (PTSA) $\left(\mathrm{C}_{7} \mathrm{H}_{8} \mathrm{O}_{3} \mathrm{~S} \cdot \mathrm{H}_{2} \mathrm{O}\right.$, Sigma Aldrich, > 98.5\%, 402885) in catalytic testing. Silicone oil bath (technical quality) is used in a catalytic test. A Dean-Stark instrument was adapted to remove water that was formed during the reaction.

\section{Procedure}

Mesoporous ZSM-5 (ZSM-5) was synthesized based on work previously reported by Eimer et al. [16] and Gonçalves et al. [17]. Sodium aluminate, $0.7748 \mathrm{~g}$ was added into $22.50 \mathrm{~mL}$ TEOS and stirred for $30 \mathrm{~min}$. After stirring, $10.17 \mathrm{~mL}$ of TPAOH and $68.2 \mathrm{~mL}$ of water were added into the resulting mixture to achieve a total composition of $1 \mathrm{SiO}_{2}: \mathrm{xAl}_{2} \mathrm{O}_{3}: 0.2 \mathrm{TPAOH}: 38 \mathrm{H}_{2} \mathrm{O} \quad(\mathrm{x}-=-$ $\left(\mathrm{SiO}_{2} / \mathrm{Al}_{2} \mathrm{O}_{3}\right)^{-1}, \mathrm{x}-=1 / 40$ or mole ratio of $\left.\mathrm{Si} / \mathrm{Al}=20\right)$. The mixture was agitated for $15 \mathrm{~h}$ and transferred into polyethylene bottle. The mixture was heated at $80^{\circ} \mathrm{C}$ for $48 \mathrm{~h}$. Following hydrothermal treatment, the mixture was cooled down to room temperature then $9.47 \mathrm{~g}$ of CTAB
$\left(\mathrm{SiO}_{2} / \mathrm{CTAB}=3.85\right)$ was added. The mixture was stirred for another $30 \mathrm{~min}$ and leave to age at ambient temperature for $3 \mathrm{~h}$. The resulting powder was filtered and washed thoroughly with water until the $\mathrm{pH}$ of the supernatant is neutral. The powder was then dried at $60^{\circ} \mathrm{C}$ for $48 \mathrm{~h}$ followed by calcination under a flow of $\mathrm{N}_{2}$ gas at $550{ }^{\circ} \mathrm{C}$ for $1 \mathrm{~h}$. The calcination was continued in the air at the same temperature for another $6 \mathrm{~h}$.

Hierarchical porous aluminosilicate catalyst (AMS) was prepared by modification of the synthesis of mesoporous ZSM-5 method [17] and mesoporous titanosilicates [16]. Sodium aluminate was dissolved in a solution of TEOS by stirring for $30 \mathrm{~min}$. TPAOH and water were added into the reaction mixture and stirred for another $15 \mathrm{~h}$ at room temperature. The mixture was then transferred into a polypropylene autoclave and heated at $80{ }^{\circ} \mathrm{C}$ for $24 \mathrm{~h}$. CTAB, used as a mesophase forming agent (a molar ratio of $\mathrm{SiO}_{2} / \mathrm{CTAB}=3.85$ ), was added after the reaction mixture was cooled at room temperature with gentle stirring for $30 \mathrm{~min}$. The mixture was then aged at room temperature for $3 \mathrm{~h}$. The solid was separated from the supernatant by centrifugation and washed with distilled water until the $\mathrm{pH}$ of the supernatant was 7. Finally, the solid was dried at $60^{\circ} \mathrm{C}$ for $24 \mathrm{~h}$ and calcined at $550^{\circ} \mathrm{C}$ for $1 \mathrm{~h}$ in $\mathrm{N}_{2}$ and $6 \mathrm{~h}$ in air to remove any organic compounds. The amount of $\mathrm{NaAlO}_{2}$ was varied to achieve the $\mathrm{SiO}_{2} / \mathrm{Al}_{2} \mathrm{O}_{3}$ ratios of 20 , 40 , and 80 . The synthesized aluminosilicates were labeled as AMS-11, AMS-34, and AMS-40 respectively with the number is corresponded to the $\mathrm{SiO}_{2} / \mathrm{Al}_{2} \mathrm{O}_{3}$ ratios as shown in EDX results. Another type of amorphous mesoporous aluminosilicate (AAS) was prepared using a similar procedure but $\mathrm{TPAOH}$ was replaced with $\mathrm{NaOH}$. Detail composition of chemicals that were used in the synthesis of aluminosilicate and ZSM-5 were summarized in Table 1.

In order to produce hydrogen formed catalyst, all the synthesis products were treated with ammonium acetate solution $(0.5 \mathrm{~mol} / \mathrm{L})$ at $60^{\circ} \mathrm{C}$ for $3 \mathrm{~h}$. The solids were centrifuged and washed thoroughly with distilled water before drying overnight at $110{ }^{\circ} \mathrm{C}$ and calcined at $550{ }^{\circ} \mathrm{C}$ for $1 \mathrm{~h}$ in $\mathrm{N}_{2}$ and $6 \mathrm{~h}$ in air. 
Table 1. Hydrothermal conditions and chemical compositions for the synthesis of ZSM-5 and aluminosilicate catalysts

\begin{tabular}{clcccccccc}
\hline \multirow{2}{*}{ Entry } & \multirow{2}{*}{ Catalysts } & \multicolumn{3}{c}{ Chemical composition } & \multicolumn{3}{c}{ Hydrothermal condition } \\
\cline { 3 - 9 } & & TEOS $(\mathrm{mL})$ & $\mathrm{NaAlO}_{2}(\mathrm{~g})$ & $\mathrm{TPAOH}(\mathrm{mL})$ & $\mathrm{CTAB}(\mathrm{g})$ & $\mathrm{NaOH}(\mathrm{g})$ & $\mathrm{H}_{2} \mathrm{O}(\mathrm{mL})$ & $\mathrm{T},{ }^{\circ} \mathrm{C}$ & $\mathrm{Time}, \mathrm{h}$ \\
\hline 1 & ZSM-5 & 22.50 & 0.7748 & 10.17 & 9.47 & - & 68.2 & 80 & 48 \\
2 & AMS-40 & 22.50 & 0.7748 & 10.17 & 9.47 & - & 68.2 & 80 & 24 \\
3 & AMS-34 & 22.50 & 0.3887 & 10.17 & 9.47 & - & 68.2 & 80 & 24 \\
4 & AMS-11 & 22.50 & 0.1934 & 10.17 & 9.47 & - & 68.2 & 80 & 24 \\
5 & AAS & 45.00 & 1.5496 & - & 18.93 & 1.56 & 130.0 & 80 & 24 \\
\hline
\end{tabular}

\section{Characterization}

Powder X-ray diffraction (XRD) patterns of the solids samples were collected on Philips X'pert XRD instrument with $\mathrm{Cu} \mathrm{Ka}$ radiation with a step size of $0.02^{\circ}$ and counting time of $10 \mathrm{sec}$. The samples were ground in agate mortar before analysis. Data were recorded in the $2 \theta$ range of $5-50^{\circ}$. Fourier transform infrared (FTIR) spectra of the samples were recorded on a Shimadzu spectrophotometer using the $\mathrm{KBr}$ pellet technique, in the range of $400-4000 \mathrm{~cm}^{-1}$ with a spectral resolution of $4 \mathrm{~cm}^{-1}$, 45 scans, at $20^{\circ} \mathrm{C}$.

The types and amount of acid sites were determined by pyridine adsorption. Before measurement of pyridine adsorption, the samples were pressed to thin wafers (around $10 \mathrm{mg} / \mathrm{cm}^{2}$ ) and placed into a sample holder. The sample disks were evacuated at $400{ }^{\circ} \mathrm{C}$ for $4 \mathrm{~h}$ in the $\mathrm{N}_{2}$ and cooled to room temperature. Then 2 drops of pyridine were exposed near the disks at room temperature. After the adsorption at room temperature for $1 \mathrm{~h}$, the infrared spectra were recorded. The desorption procedure was conducted at 150 for $3 \mathrm{~h}$ in order to determine the acidity of Lewis and Brønsted acid sites by evaluating the amount of remaining adsorbed pyridine after evacuation at $150^{\circ} \mathrm{C}$. The concentrations of Brønsted (B) and Lewis (L) acid sites were calculated from the peak areas of adsorbed pyridine at around 1540 and $1450 \mathrm{~cm}^{-1}$, using $\varepsilon(\mathrm{B})$ and $\varepsilon(\mathrm{L})$ extinction coefficients of 1.88 and $1.42 \mathrm{~cm} \cdot \mathrm{mmol}^{-1}$, respectively [18].

Nitrogen physisorption isotherms were collected on a Quantachrome Nova version 10.01. The materials were degassed for $5 \mathrm{~h}$ at $300{ }^{\circ} \mathrm{C}$, prior to analysis. Brunauer, Emmett, and Teller (BET) calculations were used to determine the material surface area. Mesopore size distributions were calculated using the Barrett, Joyner, and Halenda (BJH) method. Transmission Electron Microscopy (TEM) images were taken with a JEM 1400 instrument operating at an accelerating voltage of $120 \mathrm{kV}$.

\section{Catalytic performance}

Acetalization reaction was carried out by mixing aldehyde with propylene glycol in a $50 \mathrm{~mL}$ three-necked round-bottom flask using a Dean-Stark apparatus to remove water that was formed during the reaction. About $1.12 \mathrm{mmol}$ of 3,4-dimethoxybenzaldehyde, 2.15 mmol of propylene glycol, $0.02 \mathrm{~g}$ of dried catalyst and toluene $(20 \mathrm{~mL})$ were refluxed at $106{ }^{\circ} \mathrm{C}$ for $4 \mathrm{~h}$ by immersing the flask in a temperature-controlled oil bath. Samples were taken at regular time periods and analyzed by Techcomp 7900 gas chromatography equipped with HP 88 column and FID detector. The products were also further identified using gas chromatography-mass spectrometer. The same procedure was repeated by replacing the 3,4-dimethoxybenzaldehyde with furfuraldehyde, trans-2-hexenal, 2-acetylfuran, 1acetonafton. The same procedure was conducted for the homogeneous catalyst, PTSA (0.02 g).

\section{- RESULTS AND DISCUSSION}

\section{Characterization of the Catalysts}

The synthesized aluminosilicate and ZSM-5 were characterized using XRD to confirm the formation of a crystalline structure. Fig. 1(a) shows the main peaks at $2 \theta=7-8$ and $\sim 23^{\circ}$ corresponded to the XRD pattern of ZSM-5. Other peaks of ZSM-5 were found at $\sim 14,15,21$, 24,25 , and $27^{\circ}$. The typical amorphous aluminosilicate diffraction pattern with a broad hump at $15-25^{\circ}$ were also appeared on the synthesized aluminosilicates regardless of the $\mathrm{Si} / \mathrm{Al}$ ratios. However, at higher $\mathrm{SiO}_{2} / \mathrm{Al}_{2} \mathrm{O}_{3}$ mole ratios of 34 and 40 (AMS-34 

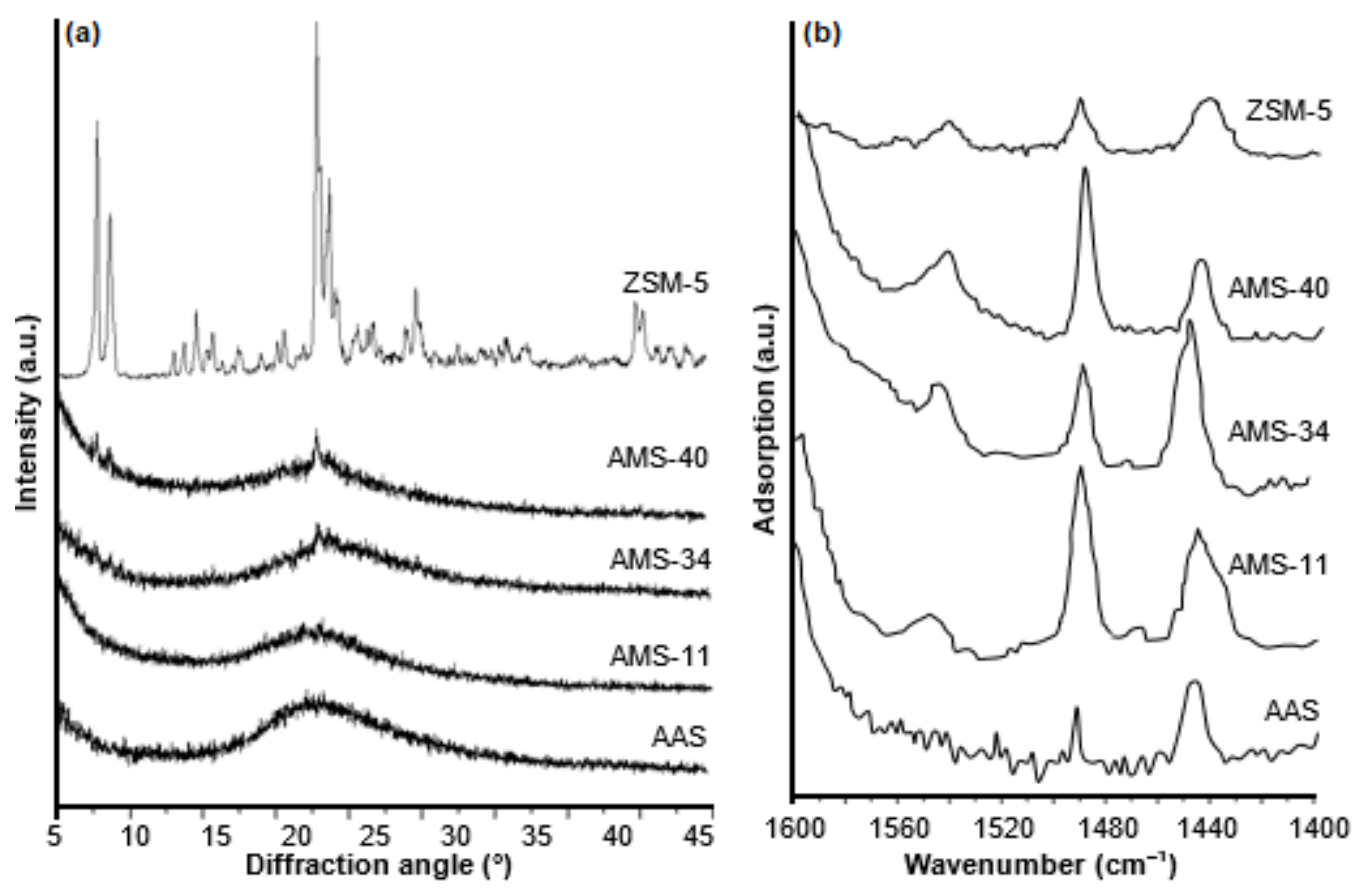

Fig 1. (a) XRD pattern of the synthesized ZSM-5 and aluminosilicates at variation $\mathrm{SiO}_{2} / \mathrm{Al}_{2} \mathrm{O}_{3}$ molar ratio; (b) The infrared spectra of the acid catalysts following pyridine adsorption and heat treatment at $150{ }^{\circ} \mathrm{C}$

and AMS-40), we observed a small diffraction peak appeared at $\sim 23^{\circ}$ that may indicate the formation of crystalline ZSM-5 phase [19].

The acidity studies on the hydrogen formed catalyst were quantified using infrared spectra with pyridine as a probe molecule. The infrared spectra of the pyridine exposed ZSM-5 and aluminosilicate following desorption at $150^{\circ} \mathrm{C}$ were shown in Fig. 1(b). The band appeared at $\sim 1444 \mathrm{~cm}^{-1}$ corresponded to the $\mathrm{C}-\mathrm{C}$ stretching of the chemisorption of pyridine on the catalysts that occurred via the coordinative bonded pyridine complex on the Lewis acid sites. The band occurred at $\sim 1544 \mathrm{~cm}^{-1}$ is attributed to the $\mathrm{C}-\mathrm{C}$ stretching vibration of the pyridinium ion on Brønsted acid sites [20-21]. The calculated amount of Brønsted and Lewis acidity were summarized in Table 2. It is clear that at high $\mathrm{SiO}_{2} / \mathrm{Al}_{2} \mathrm{O}_{3}$ ratio in aluminosilicates, the acidity increases significantly to give $\sim 1.29 \mathrm{mmol} / \mathrm{g}$ of Brønsted acidity for AMS-40. ZSM-5, with similar $\mathrm{SiO}_{2} / \mathrm{Al}_{2} \mathrm{O}_{3}$ ratios as AMS-40 however only gives $0.72 \mathrm{mmol} / \mathrm{g}$ of Brønsted acid sites. Surprisingly, the aluminosilicate synthesized by replacing TPAOH with $\mathrm{NaOH}$, AAS, only shows the Lewis acidity with no band appeared that can be used to identify the presence of Brønsted acid sites. We, however,

Table 2. Physical and acidic properties of the synthesized ZSM-5 and aluminosilicates calculated from $\mathrm{N}_{2}$ analysis data and pyridine adsorption infrared analysis

\begin{tabular}{lllcccccc}
\hline Catalysts & $\begin{array}{c}\mathrm{SiO}_{2} / \mathrm{Al}_{2} \mathrm{O}_{3} \\
\text { ratio }\end{array}$ & $\begin{array}{c}\text { Pore } \\
\text { structure }\end{array}$ & $\begin{array}{c}\text { Mesopore } \\
\text { surface area, } \\
\mathrm{m}^{2} / \mathrm{g}\end{array}$ & $\begin{array}{c}\text { Micropore } \\
\text { surface area, } \\
\mathrm{m}^{2} / \mathrm{g}\end{array}$ & $\begin{array}{c}\text { Pore } \\
\text { volume } \\
(\mathrm{mL} / \mathrm{g})\end{array}$ & $\begin{array}{c}\text { Pore } \\
\text { diameterc } \\
(\mathrm{nm})\end{array}$ & $\begin{array}{c}\text { Brønsted } \\
\text { acidity, } \\
\mathrm{mmol} / \mathrm{g}\end{array}$ & $\begin{array}{c}\text { Lewis acidity, } \\
\mathrm{mmol} / \mathrm{g}\end{array}$ \\
\hline ZSM-5 & 40 & Mesoporous & 141 & 237 & 0.39 & $4.9^{*}$ & 0.72 & 1.16 \\
AMS-40 & 40 & Hierarchical & 145 & 541 & 0.31 & 3.06 & 1.29 & 1.19 \\
AMS-34 & 34 & Hierarchical & 134 & 337 & 0.19 & 3.04 & 0.83 & 1.24 \\
AMS-11 & 11 & Hierarchical & 136 & 293 & 0.30 & 3.40 & 0.96 & 1.47 \\
AAS & 40 & Hierarchical & 278 & 284 & 0.44 & 3.81 & 0.00 & 1.05 \\
\hline
\end{tabular}

*the value is due to the interaction between nanoparticles i.e. inter-crystalline interaction 
did not show any correlation between Lewis acidity with the $\mathrm{SiO}_{2} / \mathrm{Al}_{2} \mathrm{O}_{3}$ ratios, which is not surprising due the Lewis acidity occurs as a result of the presence on $\mathrm{Al}$ intra framework [22].

The ZSM-5 and aluminosilicates were also characterized using $\mathrm{N}_{2}$ adsorption analysis (Fig. 2) with the surface area, calculated micropore and mesopore areas, and pore volume was summarized in Table 2. The adsorption-desorption isotherm of ZSM-5 is a typical type IV isotherm with capillary condensation at high relative pressure between 0.6 and 0.9 , suggesting a relatively large mesoporous size. The aluminosilicates with $\mathrm{SiO}_{2} / \mathrm{Al}_{2} \mathrm{O}_{3}$ ratios of 34 and 40 , AMS-34, AMS-40 and AAS also showed a typical pattern of type IV structure accompanied with the hysteresis loop at high pressure (0.85-0.95). This occurrence corresponds to the $\mathrm{H} 4$ hysteresis loop which implies the material containing both micropores and mesopores type structure [19]. $\mathrm{N}_{2}$ adsorption isotherm of ZSM-5 and AMS-11 showed comparable adsorption with wide $\mathrm{N}_{2}$ adsorption and desorption distribution volume meanwhile the AMS-34, AMS-40, and AAS showed a narrow $\mathrm{N}_{2}$ distribution volume. These differences suggest the formation of hierarchical structure in AMS-34, AMS-40, and AAS. The calculated data from $\mathrm{N}_{2}$ adsorption analysis summarized in Table 2 shows the AMS- 40 has a high surface area with a pore volume of $\sim 0.311 \mathrm{~cm}^{3} / \mathrm{g}$. Although all the samples showed pore diameter of $\sim 3$ $\mathrm{nm}$, we believe that the value obtained from ZSM-5 is due to the inter-particulate interaction that generally occurs on nanosize particles. This will later support by TEM analysis.

The morphology of the ZSM-5 and the aluminosilicates were analyzed using TEM analysis as shown in Fig. 3. The aluminosilicates showed irregular shapes with average crystallite size $\sim 100 \mathrm{~nm}$. The AMS40, AMS-34, AMS-11 and AAS images also showed a different light intensity with the lighter density of electron transmission features represented the formation of mesopores structure [23]. The features were more visible in aluminosilicate at high $\mathrm{SiO}_{2} / \mathrm{Al}_{2} \mathrm{O}_{3}$ ratios, AMS-40 indicating the formation of intra-crystalline mesoporous structure within the nanoparticles of aluminosilicate [24].The observation, however, does not appear on ZSM-5. In relation to the mesopores area and pore diameter obtained from $\mathrm{N}_{2}$ adsorption data of the
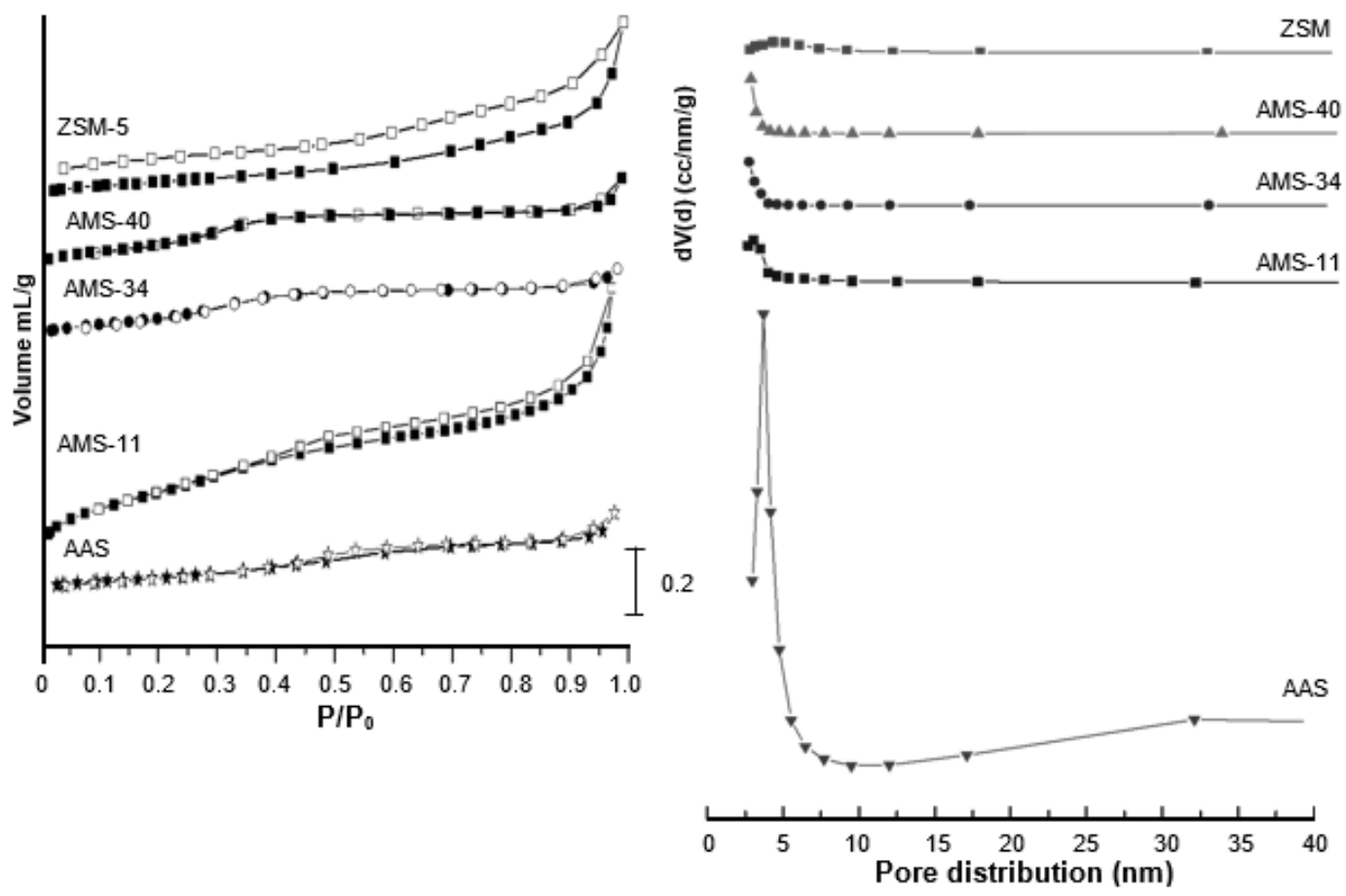

Fig 2. $\mathrm{N}_{2}$ adsorption isotherms and pore distribution of ZSM-5 and aluminosilicates at different $\mathrm{SiO}_{2} / \mathrm{Al}_{2} \mathrm{O}_{3}$ ratios 

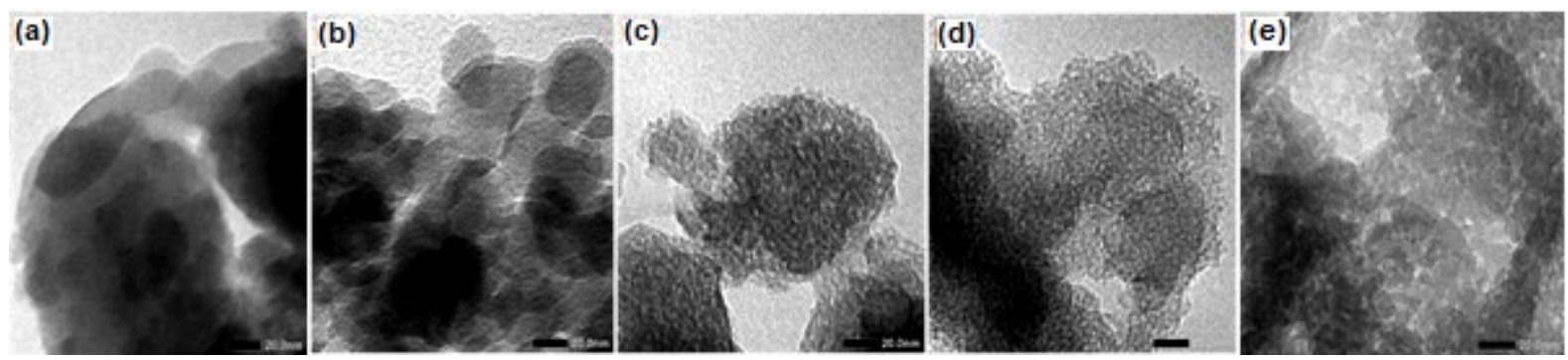

Fig 3. The TEM images of (a) ZSM-5, aluminosilicate nanoparticles, (b) AMS-11, (c) AMS-34, (d) AMS-40, (e) AAS

ZSM-5 in Table 2, we suggest that the mesopores structure that was determined in ZSM-5 is very likely to arise from the interaction between nanoparticles rather than the formation of the intra-crystalline mesoporous structure as shown in aluminosilicates. Therefore, we can conclude that the aluminosilicates formed a hierarchical micro and mesopores structures within the framework.

\section{Catalytic Activity}

The synthesized hydrogen formed ZSM-5 and aluminosilicates was used as an acid catalyst in acetalization of 3,4-dimethoxybenzaldehyde with propylene glycol. The conversion, the amount of acid catalysts and the turn over number, TON were summarized in Table 3. The reaction was also carried out on homogeneous PTSA catalyst. We observed that the homogenous PTSA produced high catalytic conversion $\sim 87 \%$ followed with AS-40 to give $\sim 83 \%$. On aluminosilicates catalysts, the conversion reduced significantly with low $\mathrm{SiO}_{2} / \mathrm{Al}_{2} \mathrm{O}_{3}$ content to give only $31 \%$ conversion on AMS-11. Meanwhile, for ZSM-5 and aluminosilicate synthesized using $\mathrm{NaOH}$, AAS showed no apparent conversion within $4 \mathrm{~h}$ of reaction. We relate the catalytic performance with the amount of acid sites determined using pyridine adsorption method. Although the AAS aluminosilicate possesses Lewis acid sites on the surface, the lack of Brønsted acidity makes the catalyst inactive for acetalization reaction. The lack of catalytic performance was also observed on ZSM5.However, the only reason to justify why the ZSM-5 was inactive to catalyze the reaction is due to the low amount of Brønsted acid, $\sim 0.0162 \mathrm{mmol}$. A linear relationship between acidity and catalytic performance was further supported by the TON of mesoporous aluminosilicate catalysts, with the TON increases significantly on the catalysts at high $\mathrm{SiO}_{2} / \mathrm{Al}_{2} \mathrm{O}_{3}$ ratios. It is interesting to see that the TON of all mesoporous aluminosilicates was higher in comparison to the homogeneous PTSA catalyst.

Catalytic reaction of the synthesized aluminosilicates were further attempted on acetalization of furfuraldehyde and trans-2-hexenal; and also ketalization of 2acetylfuran and 1-acetonafton. The kinetic study of the acetalization and ketalization of aldehyde and ketone with propylene glycol were carried out at $106^{\circ} \mathrm{C}$ for $250 \mathrm{~min}$.

Table 3. Acetalization of 3,4-dimethoxybenzaldehyde in the presence of propylene glycol on ZSM-5, aluminosilicate catalysts at different $\mathrm{Si} / \mathrm{Al}$ ratios and homogeneous PTSA catalyst. Data was obtained at $240 \mathrm{~min}$ of reaction

\begin{tabular}{lccr}
\hline Catalysts & Conversion $(\%)$ & Acid sites $(\mathrm{mmol})^{\mathrm{a}}$ & TON $^{\mathrm{b}}$ \\
\hline ZSM-5 & 0.00 & 0.0162 & 0 \\
AMS -11 & 31.46 & 0.0216 & 28704 \\
AMS-34 & 48.89 & 0.0189 & 61298 \\
AMS-40 & 83.33 & 0.0293 & 95619 \\
AAS & 0.00 & 0 & 0 \\
PTSA & 87.5 & 0.1277 & 20353 \\
\hline
\end{tabular}

${ }^{a}$ Acid sites of solid acid catalysts were obtained based on Bronsted acidity calculated from pyridine adsorption studies times with the amount of catalyst used in the reaction. For homogeneous catalyst PTSA, acid site was determined based on the amount of PTSA used in the reaction.

${ }^{\mathrm{b}}$ Turnover number, TON is calculated based on the amount of aldehyde conversion over active acid sites. 
The plot of conversion against reaction time was shown in Fig. 3. AMS-40showed superior activity for all acetalization reactions, however, the conversion reduced from acetalization of 3,4-dimethoxybenzaldehyde to furfuraldehyde and trans-2-hexenal. Note that all aluminosilicate catalysts were inactive in ketalization reaction. In general, acetalization only required the presence of weak acid, meanwhile, the ketalization reaction often catalyzed by strong acids, like sulfuric acid, chloric acid, or PTSA [2]. Ketone molecules are also less reactive in comparison to the aldehyde in a chemical reaction involving nucleophilic addition [25]. This is due to the steric hindrance and electronic factor cause by two substituent groups that create the stronger steric effect and complicates the reaction with the nucleophile.

Table 4 summarized the catalytic performances of AMS-40 and PTSA on acetalization of 3,4dimethoxybenzaldehyde, furfuraldehyde, and trans-2hexenal. It is interesting to see that the aluminosilicate catalyst, AMS- 40 showed $100 \%$ selectivity towards the desired product with the conversion were not far from the value obtained when using PTSA in both acetalization of 3,4-dimethoxybenzaldehyde and furfuraldehyde. Although the conversion of trans-2-hexenal is only $30 \%$ which is significantly lower than PTSA $\sim 89 \%$, the catalyst still shows $100 \%$ selectivity towards the desired acetalization product. Different conversion reaction of AMS-40 towards 3,4-dimethoxybenzaldehyde, furfuraldehyde, and trans-2-hexenal can be explained that different geometric shape structure of the aldehyde compound made it easy to diffuse into pores will give a greater conversion.

In this paper, we do not perform the reusability of the prepared catalysts since our experimental results show that it was not good of reusability. The catalysts conversion declined after two times and several uses which might aluminosilicates heterogeneous catalysts have mayor amorf particles. Therefore, it was brittle and easy to broke after several used. The Brønsted acid also found evaporated after three times uses of catalysts based on diffractogram of pyridine desorption (Do not appear in the paper).

\section{Structure and Reactivity of Aluminosilicates}

The synthesized aluminosilicate nanoparticles showed the presence of hierarchical micro and mesoporous structure that in relation to its catalytic performance in acetalization reaction proved the catalyst is active with high selectivity towards acetalization product. In comparison to the ZSM-5 synthesized using

Table 4. Aldehyde conversion and product selectivity on AMS-40 catalysts and homogeneous PTSA on three different types of aldehydes; 3,4-dimethoxy-benzaldehyde, furfuraldehyde and trans-2-hexenal. The reaction was carried out for $24 \mathrm{~h}$ at $106^{\circ} \mathrm{C}$

\begin{tabular}{|c|c|c|c|c|c|c|c|}
\hline \multirow{2}{*}{ Entry } & \multicolumn{3}{|c|}{ Acetalization reaction } & \multicolumn{2}{|c|}{ Conversion (\%) } & \multicolumn{2}{|c|}{ Selectivity (\%) } \\
\hline & Aldehyde & Alcohol & Product & AMS-40 & PTSA & AMS-40 & PTSA \\
\hline 1 & $\begin{array}{c}\text { 3.4-dimethoxy- } \\
\text { benzaldehyde } \\
\text { •.0. }\end{array}$ & $\begin{array}{l}\text { Propylene } \\
\text { glycol }\end{array}$ & & 83 & 87 & 100 & 95 \\
\hline 2 & $\begin{array}{c}\text { furfuraldehyde } \\
.0\end{array}$ & $\begin{array}{l}\text { Propylene } \\
\text { glycol }\end{array}$ & & 35 & 26 & 100 & 94 \\
\hline 3 & $\begin{array}{c}\text { trans-2-hexenal } \\
\cdot{ }^{\circ} \cdot\end{array}$ & $\begin{array}{c}\text { Propylene } \\
\text { glycol }\end{array}$ & & 30 & 89 & 100 & 13 \\
\hline
\end{tabular}


similar structure directing agent and with similar $\mathrm{Si} / \mathrm{Al}$ ratio, the aluminosilicates AMS-40 showed high conversion and selectivity meanwhile ZSM-5 showed negligible activity. The AMS-40 also showed comparable catalytic performance to the homogeneous PTSA particularly in the acetalization of 3.4-dimethoxybenzaldehyde. It is also interesting that the aluminosilicates showed negligible activity in ketalization reaction. Owing to the reactivity of ketone in comparison to aldehyde, due to the two substituted groups present in ketone gives a positive induction effect with more clustering constituents cause the carbon in the carbonyl group to have less electron deficiency, resulting in lower reactivity to the nucleophile [25]. Studies reported previously that the acidity of aluminosilicate is weaker than the USY zeolite but slightly stronger than MCM-41 [2]. The acidity of hierarchical porous heterogeneous aluminosilicate is relatively too weak to catalyze the ketalization reaction.

TEM analysis provides clear evidence on the differences in physical morphology of the aluminosilicate and ZSM-5. As shown in TEM images, the aluminosilicates particularly at high Si/Al ratios, AMS-40 and AMS-34 showed the apparent formation of intracrystalline mesopores. Although the pore diameter obtained from $\mathrm{N}_{2}$ adsorption analysis summarized in Table 2 shows no significant differences between ZSM- 5 and aluminosilicates, the TEM, however, suggested that the diameter derived in ZSM-5 were most likely originated from the interaction between the nanoparticles that created inter-crystallite pores. However, for aluminosilicates, the presence of hollow structure observed on the TEM images, suggesting the presence of pore within the aluminosilicate nanoparticles, i.e. intracrystallite pore. The low amount of Bronsted acid in ZSM5 was determined as a responsible factor that contributed to the lack of activity acetylation reaction. We also observed that the aluminosilicate synthesized using $\mathrm{NaOH}$, AAS failed to show any activity in acetalization reaction despite the presence of mesopores structure. Detail analysis of surface acidity revealed the presence of only Lewis acidity. This further suggested that the reaction occurs directly on Brønsted acidity, with Lewis acid site plays no active role in the catalytic reaction.

Aluminosilicates indicated more selective than PTSA according to Table 4. It because traditional heterogeneous catalyst (e.g. metals or metal oxides) commonly has more active sites (more than one active site) meanwhile homogeneous catalyst (such as PTSA) only have a single active site, suspiciously [26]. We implied that acetalization reaction using aluminosilicates occurred on the same active site as well as a single active site in PTSA since Bronsted acids have a role play. In addition, the intra-crystalline pore in TEM images possible to have enough wide pores for molecules reactant and products to diffuse into and outside pores. Concerning this reason, aluminosilicates have a positive effect on reactant conversion and product selectivity.

\section{- CONCLUSION}

We have investigated the effect of aluminosilicate morphology and acidity as an acid catalyst for acetalization reaction. The results highlighted two crucial factors affecting the catalytic performance of aluminosilicate, i.e. hierarchical structures with intracrystalline pores and Brønsted acidity. In comparison to the homogeneous PTSA catalyst, hierarchical aluminosilicate has good potential as a selective catalyst for acetalization reaction with good conversion. The different activity of aluminosilicates catalysts in the conversion of an aldehyde to acetal also affected by the different geometrical structure of aldehyde used. The lack of Bronsted acidity on the aluminosilicate synthesized using $\mathrm{NaOH}$ provide further understanding of the mechanism of reaction that occurs on Brønsted acid sites rather than Lewis acid sites. The strength of Brønsted acid sites and intraparticle mesopore of catalyst taking into account on the acetalization activity, as well as the aldehyde structures.

\section{- ACKNOWLEDGMENTS}

The authors gratefully acknowledge the research funding provided by the Ministry of Research, Technology and Higher Education of Indonesia. 


\section{- REFERENCES}

[1] Rowe, D.J., 2005, "Aroma chemicals I: C, H, O compounds" in Chemistry and Technology of Flavors and Fragrances, CRC Press Blackwell Publishing Ltd., Canada, 56-84.

[2] Climent, M.J., Corma, A., and Velty, A., 2004, Synthesis of hyacinth, vanilla, and blossom orange fragrances: The benefit of using zeolites and delaminated zeolites as catalysts, Appl. Catal., A, 263 (2), 155-161.

[3] Justus, J., Vinu, A., Devassy, B.M., Balasubramanian, V.V., Bohringer, W., Fletcher, J., and Halligudi, S.B., 2008, Highly efficient and chemoselective catalyst system for the synthesis of blossom orange fragrance and flavoring, Catal. Commun., 9 (7), 1671-1675.

[4] Umbarkar, S.B., Kotbagi, T.V., Biradar, A.V., Pasricha, R., Chanale, J., Dongare, M.K., Mamede, A.S., Lancelot, C., and Payen, E., 2009, Acetalization of glycerol using mesoporous $\mathrm{MoO}_{3} / \mathrm{SiO}_{2}$ solid acid catalyst, J. Mol. Catal. A: Chem., 310 (1-2), 150-158.

[5] Corma, A., 1997, Solid acid catalysts, Curr. Opin. Solid State Mater. Sci., 2 (1), 63-75.

[6] Sheldon, R.A., Arends, I.W.C.E., and Hanefeld, U., 2007, Green Chemistry and Catalysis, Wiley-VCH Verlag GmbH \& Co. KGaA, Weinheim.

[7] Augustine, J.K., Bombrun, A., Sauer, W.H.B., and Vijaykumar, P., 2012, Highly efficient and chemoselective acetalization and thioacetalization of aldehydes catalyzed by propylphosphonic anhydride $\left({ }^{\circ} \mathrm{T} 3 \mathrm{P}\right)$ at room temperature, Tetrahedron Lett., 53 (37), 5030-5033.

[8] Climent, M.J., Corma, A., Velty, A., and Susarte, M., 2000, Zeolites for the production of fine chemicals: Synthesis of the fructone fragrancy, J. Catal., 196 (2), 345-351.

[9] Rodriguez, I., Climent, M.J., Iborra, S., Fornds, V., and Corma, A., 2000, Use of delaminated zeolites (ITQ-2) and mesoporous molecular sieves in the production of fine chemicals: Preparation of dimethylacetals and tetrahydropyranylation of alcohols and phenols, J. Catal., 192 (2), 441-447.

[10] Thomas, B., Prathapan, S., and Sugunan, S., 2004, Effect of pore size on the catalytic activities of K-10 clay and $\mathrm{H}$-zeolites for the acetalization of ketones with methanol, Appl. Catal., A, 277 (1-2), 247-252.

[11] Liang, X.Z., Gao, S., Wang, W.J., Cheng, W.P., and Yang, J.G., 2007, Comparative research on the catalytic activities of different molecular sieves for acetalization and ketalization, Chin. Sci. Bull., 52 (13), 1780-1784.

[12] Manjunathan, P., Maradur, S.P., Halgeri, A.B., and Shanbhag, G.V., 2015, Room temperature synthesis of solketal from acetalization of glycerol with acetone: Effect of crystallite size and the role of acidity of beta zeolite, J. Mol. Catal. A: Chem., 396, 47-54.

[13] Freitas, F.A., Licursi, D., Lachter, E.R., Galletti, A.M.R., Antonetti, C., Brito, T.C., Sandra, R., and Nascimento, R.S.V., 2016, Heterogeneous catalysis for the ketalisation of ethyl levulinate with 1,2dodecanediol: Opening the way to a new class of bio-degradable surfactants, Catal. Commun., 73, 84-87.

[14] Hartati, Prasetyoko, D., Santoso, M., Bahruji, H., and Triwahyono, S., 2014, Highly active aluminosilicates with a hierarchical porous structure for acetalization of 3,4dimethoxybenzaldehyde, Jurnal Teknologi, 69 (5), 2180-3722.

[15] Hartati, Prasetyoko, D., and Santoso, M., 2016, Cyclic acetalization of furfural on porous aluminosilicate acid catalysts, Indones. J. Chem., 16 (3), 289-296.

[16] Eimer, G.A., Díaz, I., Sastre, E., Casuscelli, S.G., Crivello, M.E., Herrero, E.R., and Perez-Pariente J., 2008, Mesoporous titanosilicates synthesized from TS-1 precursors with enhanced catalytic activity in the $\alpha$-pinene selective oxidation, Appl. Catal., A, 343 (1-2), 77-86.

[17] Gonçalves, M.L., Dimitrov, L.D., Jordão, M.H., Wallau, M., and Urquieta-González, E.A., 2008, Synthesis of mesoporous ZSM- 5 by crystallisation of aged gels in the presence of cetyltrimethyl ammonium cations, Catal. Today, 133-135, 69-79.

[18] Emeis, C.A., 1993, Determination of integrated molar extinction coefficients for infrared 
absorption bands of pyridine adsorbed on solid acid catalysts, J. Catal., 141 (2), 347-354.

[19] Thommes, M., 2010, Physical adsorption characterization of nanoporous materials, Chem. Ing. Tech., 82 (7), 1059-1073.

[20] Jin, F., and Li, Y., 2009, A FTIR and TPD examination of the distributive properties of acid sites on ZSM-5 zeolite with pyridine as a probe molecule, Catal. Today, 145 (1-2), 101-107.

[21] Hensen, E.J.M., Poduval, D.G., Degirmenci, V., Ligthart, D.A.J.M., Chen, W., Maugé, F., Rigutto, M.S., and van Veen, J.A.R., 2012, Acidity characterization of amorphous silica-alumina, $J$. Phys. Chem. C, 116 (40), 21416-21429.

[22] Almutairi, S.M.T., Mezari, B., Filonenko, G.A., Magusin, P.C.M.M., Rigutto, M.S., Pidko, E.A., and Hensen, E.J.M., 2013, Influence of extra framework aluminum on the Brønsted acidity and catalytic reactivity of faujasite zeolite, ChemCatChem, 5 (2), 452-466.

[23] Li, C., Wang, Y., Shi, B., Ren, J., Liu, X., Wang, Y., Guo, Y., Guo, Y., and Lu, G., 2009, Synthesis of hierarchical MFI zeolite microspheres with stacking nanocrystals, Microporous Mesoporous Mater., 117 (1-2), 104-110.

[24] Zhu, H., Liu, Z., Kong, D., Wang, Y., Yuan, X., and Xie, Z., 2009, Synthesis of ZSM-5 with intracrystal or intercrystal mesopores by polyvinyl butyral templating method, J. Colloid Interface Sci., 331 (2), 432-438.

[25] McMurry, J., 1996, Organic Chemistry, $4^{\text {th }}$ Ed., Brooks/Cole Publishing Company, USA, 726-727.

[26] Farnetti, E., Di Monte, R., and Kašpar, J., 2009, "Homogeneous and Heterogeneous Catalysis" in Inorganic and Bio-Inorganic Chemistry, Encyclopedia of Life Support Systems (EOLSS), Vol. II, 50-86. 